\title{
Preoperative right ventricular dysfunction requires high vasoactive and inotropic support during off-pump coronary artery bypass grafting
}

\author{
Tatsuya Kunigo $^{1}$ (]) Yusuke Yoshikawa ${ }^{2} \cdot$ Shuji Yamamoto $^{1} \cdot$ Michiaki Yamakage $^{2}$
}

Received: 8 October 2020 / Accepted: 16 November 2020 / Published online: 3 January 2021

(c) The Japanese Association for Thoracic Surgery 2021

\begin{abstract}
Objectives The association of preoperative RV function with hemodynamics during OPCAB or emergency conversion is not clear. The aim of this study was to investigate the association of vasoactive-inotropic score with tricuspid annular plane systolic excursion and tricuspid regurgitation in off-pump coronary artery bypass grafting, and to calculate the optimal cutoff value of tricuspid annular plane systolic excursion to predict emergency conversion to cardiopulmonary bypass.

Methods Patients over 20 years of age who had undergone off-pump coronary artery bypass grafting between April 2015 and March 2020 were enrolled in this study. We retrospectively assessed the association of intraoperative maximum "vasoactive-inotropic score", a weighted sum of various inotropes and vasoconstrictors, with tricuspid annular plane systolic excursion and tricuspid regurgitation. A receiver operating characteristic curve of conversion on tricuspid annular plane systolic excursion was also constructed.

Results 135 patients were included in final analysis. Conversion was performed in 10 cases. Multiple regression analysis showed that tricuspid annular plane systolic excursion, mild or more tricuspid regurgitation and experienced surgeon were significantly related to vasoactive-inotropic score. The receiver operating characteristic curve to predict conversion by tricuspid annular plane systolic excursion showed an optimal cut-off value of $15.0 \mathrm{~mm}$ and area under the curve of 0.808 .

Conclusions Tricuspid annular plane systolic excursion and tricuspid regurgitation were associated with vasoactive-inotropic score in off-pump coronary artery bypass grafting. The optimal cut-off value of tricuspid annular plane systolic excursion to predict emergency conversion was $15 \mathrm{~mm}$.
\end{abstract}

Keywords Tricuspid annular plane systolic excursion · Tricuspid regurgitation · Right ventricular dysfunction · Off-pump coronary artery bypass grafting $\cdot$ Vasoactive-inotropic score

Tatsuya Kunigo

tatsuya_9250@yahoo.co.jp

Yusuke Yoshikawa

yusuke_19_@hotmail.com

Shuji Yamamoto

yshuji@giga.ocn.ne.jp

Michiaki Yamakage

michiaki_yamakage@icloud.com

1 Department of Anesthesiology, Obihiro Kosei General Hospital, 1 West 14 South 10, Obihiro, Hokkaido 080-0024, Japan

2 Department of Anesthesiology, Sapporo Medical University School of Medicine, 291 South 1 West 16, Chuo-ku, Sapporo, Hokkaido 060-8543, Japan

\section{Introduction}

Although off-pump coronary artery bypass grafting $(\mathrm{OPCAB})$ is associated with lower mortality than coronary artery bypass grafting $(\mathrm{CABG})$ in cardiopulmonary bypass (CPB) for high-risk patients [1-3], intraoperative hemodynamic instability results in emergency conversion from offpump to on-pump CABG and higher morbidity and mortality than those with completed OPCAB or scheduled CPB [4-12].

Previous studies have shown that urgent surgery $[5,6$, $8]$, triple vessel disease (TVD) $[6,8,13]$, left main coronary artery (LMT) disease [7, 8, 12, 13], congestive heart failure (CHF) $[6,8,11,13,14]$ and previous CABG $[5,8$, 11] are preoperative risk factors of emergency conversion. In addition, left ventricular dysfunctions including low left 
ventricular ejection fraction (LVEF) [6, 14], mitral regurgitation (MR) [12, 15], high left ventricular end diastolic pressure (LVEDP) [16] and left ventricular hypertrophy (LVH) [5] have been shown to be factors causing hemodynamic instability that can result in the need for emergency conversion.

It has been reported that right ventricular ejection fraction (RVEF) was decreased during anastomosis of the obtuse marginal (OM) artery in OPCAB [17] and that a suctiontype stabilizer caused more anterior displacement and compression of the right ventricle (RV) than the left ventricle (LV) [18]. However, the association of preoperative RV function with hemodynamics during OPCAB or emergency conversion is not clear.

The vasoactive-inotropic score (VIS) as a weighted sum of various inotropes and vasoconstrictors was suggested to predict mortality and morbidity after pediatric cardiac surgery in the intensive care unit (ICU) [19, 20]. A high VIS can predict postoperative unfavorable outcomes in not only children but also adults [21]. In addition, preoperative RV dysfunction is an independent risk factor for a high VIS after adult cardiac surgery [22].

In this study, we investigated the associations of preoperative tricuspid annular plane systolic excursion (TAPSE) and tricuspid regurgitation (TR) with intraoperative maximum VIS in OPCAB, and we calculated the optimal cut-off value of TAPSE to predict emergency conversion to on-pump CABG.

\section{Subjects}

This study was approved by the Institutional Review Board of Obihiro Kosei General Hospital (No. 2020-005) and was conducted in accordance with the Declaration of Helsinki and EQUATOR guidelines. The Institutional Review Board waived the requirement for written informed consent from the patients because this was a retrospective observational study and the data were analyzed anonymously. This research was carried out without funding.

Medical records of Obihiro Kosei General Hospital between April 2015 and March 2020 were retrospectively reviewed. Patients over 20 years of age who had undergone OPCAB were enrolled in this study. Exclusion criteria were re-CABG, scheduled on-pump CABG and preoperative intra-aortic balloon pumping (IABP).

\section{Methods}

None of the patients were premedicated before general anesthesia. After a peripheral venous and arterial line had been inserted, midazolam $(0.05-0.15 \mathrm{mg} / \mathrm{kg})$ or propofol $(1-2 \mathrm{mg} / \mathrm{kg}$ ) was administered for induction of anesthesia.
The patients were intubated after administration of rocuronium $(0.6-1.2 \mathrm{mg} / \mathrm{kg})$ and fentanil $(1-5 \mathrm{mcg} / \mathrm{kg})$ and $/$ or remifentanil $(0.1-0.5 \mathrm{mcg} / \mathrm{kg} / \mathrm{min})$, and then a transesophageal echo probe, central vein catheter and pulmonary artery catheter were inserted. Patients were monitored by electrocardiography, a pulse oximeter, invasive and non-invasive arterial pressures, transesophageal echocardiography, central venous pressure, pulmonary arterial pressure, mixed venous oxygen saturation, cardiac output, bispectral index and regional cerebral oxygen saturation.

Anesthesia was maintained by sevoflurane (expiratory concentration of $1-2 \%)$ or propofol $(2-5 \mathrm{mcg} / \mathrm{mL}$ by target-controlled infusion) and fentanil (total dose of 10-20 $\mathrm{mcg} / \mathrm{kg})$ and $/$ or remifentanil $(0.1-0.5 \mathrm{mcg} / \mathrm{kg} / \mathrm{min})$ and rocuronium (4-8 $\mathrm{mcg} / \mathrm{kg} / \mathrm{min}$ ). For hypotension, ephedrine or phenylephrine was administered before central venous catheterization, and dopamine, dobutamine or norepinephrine was additionally administered after that by the decision of each anesthesiologist. For the hypotension derived from heart dislocation, most anesthesiologist performed firstly deep head down position and rapid fluid infusion, then inotropic or vasoactive agent administration, finally red blood cell transfusion in anemia cases. The anesthesiologist certified both by Japanese Society of Anesthesiologists Board and by Japanese Board of Perioperative Transesophageal Echocardiography was defined as an experienced anesthesiologist in this study.

The decision of on-pump or off-pump CABG was entrusted to the surgeon before operation. One training instructor (experienced surgeon) certified by the Japanese Board of Cardiovascular Surgery performed surgery or assisted instructively in all cases throughout surgery. All patients were operated by median sternotomy. Bilateral internal thoracic arteries (ITAs, only one side for diabetics), radial artery of the non-dominant hand, and saphenous veins were used as grafts. ITAs were harvested by the skeletonization technique using an ultrasonic scalpel (Harmonic Scalpel, Johnson \& Johnson, New Brunswick, New Jersey, the United States of America).

Revascularization was performed in the order of left anterior descending artery (LAD), right coronary artery (RCA) and left circumflex artery (LCX) with the aid of carbon dioxide blower and a suction tissue stabilizer (ACROBAT-i Stabilizer, Guidant, Indianapolis, Indiana, USA) and a coronary shunt tube (Clearview, Medtronic, Minneapolis, Minnesota, USA). A heart positioner (ACROBAT-i Positioner, Guidant, Indianapolis, Indiana, USA) was also used for revascularization of the RCA and LCX. The proximal side of free grafts (radial artery and saphenous vein) was anastomosed to the ascending aorta using a proximal anastomosis device (Enclose II, Novare Surgical Systems, Cupertino, California, USA) before distal anastomosis. In cases of emergency conversion to 
$\mathrm{CPB}$, the operation was continued with the heart beating on CPB. Conversion was defined as unplanned use of CPB for unacceptable hemodynamic instability based on the decision of the surgeon or anesthesiologist. After surgery, all of the patients were transferred the ICU while being intubated and sedated.

Data including demographic, historical, and perioperative variables were obtained from medical records. A medical technologist or cardiologist assessed cardiac function systematically including preoperative TAPSE and comprehensively graded TR before surgery. TAPSE was used to evaluate RV longitudinal contractility and the value less than $17 \mathrm{~mm}$ meant right ventricular contractile dysfunction. Preoperative TAPSE was retrospectively re-assessed not from motion-mode (M-mode) echocardiography recommended by "guidelines and standards" [23] but from preoperative two dimensional echocardiographic apical four chamber view in this study because there was a discrepancy between the longitudinal motion of the tricuspid lateral annulus and the incidence angle of ultrasound.

VIS was calculated as (dopamine dose + dobutamine dose) $(\mathrm{mcg} / \mathrm{kg} / \mathrm{min})+10$ times milrinone dose $(\mathrm{mcg} / \mathrm{kg} /$ $\min )+100$ times (epinephrine dose + norepinephrine dose) $(\mathrm{mcg} / \mathrm{kg} / \mathrm{min})+10,000$ times vasopressin dose (unit $/ \mathrm{kg} / \mathrm{min}$ ) $[19,20]$ and was used to evaluate intraoperative hemodynamics. Age [6], sex [16], urgent surgery [5, 6, 8], TVD [6, 8, 13], LMT disease [7, 8, 12, 13] and CHF [6, 8, 11, 13, 14] were considered to be essential or definitive variables associated with VIS without multicollinearity among the variables and were included in multivariate regression analysis. We defined the patients who required hospitalization and treatment by a cardiologist before surgery as CHF. Urgent/emergent was defined based on Japan Cardiovascular Surgery Database. Other potential variables including TAPSE, TR, LVEF [6, 14], MR [12, 15], early diastolic trans-mitral blood flow velocity divided by early diastolic lateral mitral annulus tissue velocity (E/Ea) (There was no record of LVEDP [16].), LVH [5], Canadian Cardiovascular Society functional classification (CCS classification) [5], preoperative acute myocardial infarction (AMI) [8, 14], cerebrovascular disease (CVD) [5], diabetes mellitus (DM) [5] and anesthesiologists' or surgeons' experience $[9,11]$ were used in multivariate regression analysis if their $\mathrm{P}$ values were less than 0.1 in simple regression analysis.

The primary outcome was the association of intraoperative maximum VIS with TAPSE and TR, and the optimal cut-off value of TAPSE to predict emergency conversion was also calculated by a receiver operating characteristic (ROC) curve. The secondary outcomes were variables, perioperative course (conversion probability and durations of intubation, ICU and hospital stay) and complications (mortality, respiratory failure, renal failure, stroke, wound infection and bleeding requiring a re-operation). Preoperative hemodialysis for chronic renal failure were excluded from acute kidney injury.

\section{Statistical analysis}

The Kolmogorov-Smirnov test and $F$ test were used to determine whether continuous variables followed a normal distribution and the homogeneity of variance. Continuous variables were expressed as means with standard deviation (SD) or medians with interquartile range (IQR), and they were compared using Student's $t$ test or the Mann-Whitney test. Frequencies were expressed as absolute numbers and percentages, and they were compared using the chi-square test. Multiple regression analysis was used to predict VIS based on essential or definitive variables and potential variables with a $P$ value less than 0.1 in simple regression. Variables with variance inflation factors (VIFs) of more than 5 were considered as multicollinearity. An ROC curve was constructed to calculate sensitivity, specificity and the optimal cut-off value by maximum Youden index. Area under the curve (AUC) above 0.8 was considered accurate. A $P$ value less than 0.05 was considered statistically significant. All statistical analyses were performed with EZR version 1.41 (Saitama Medical Center, Jichi Medical University, Saitama, Japan), which is a graphical user interface for $\mathrm{R}$ version 3.5.2 (The R Foundation for Statistical Computing, Vienna, Austria) [24]. More precisely, it is a modified version of R commander version 2.5-1 designed to add statistical functions frequently used in biostatistics.

\section{Results}

A total of 160 patients were enrolled in this study and data for 135 patients were analyzed (Fig. 1). Data for patients' demographic, historical and preoperative variables are shown in Table 1. Emergency conversion to cardiopulmonary bypass was performed in 10 cases (7.4\%). Intraoperative and postoperative data and details of emergency

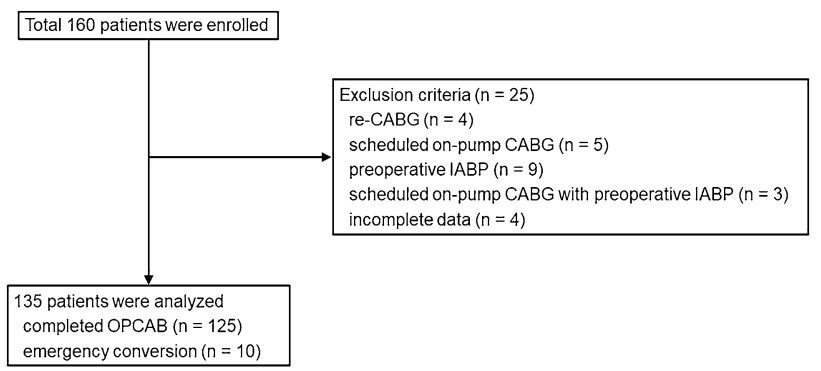

Fig. 1 Flow chart. $O P C A B$ off-pump coronary artery bypass grafting, $C A B G$ coronary artery bypass grafting, IABP intra-aortic balloon pumping 
Table 1 Patients' charasteristics

\begin{tabular}{|c|c|c|c|}
\hline Variables & $\begin{array}{l}\text { Completed OPCAB } \\
(n=125)\end{array}$ & Converted to CPB $(n=10)$ & $P$ value \\
\hline Age (year) & $69.0[60.0-76.0]$ & $74[67.8-79.5]$ & 0.11 \\
\hline Male & $98(78.4)$ & $9(90.0)$ & 0.64 \\
\hline Body mass index & $23.7[21.5-26.3]$ & $23.7[22.4-24.8]$ & 0.86 \\
\hline Urgent surgery & $11(8.8)$ & 0 & 0.71 \\
\hline \multicolumn{4}{|l|}{ ASA PS } \\
\hline$<3$ & $35(28.0)$ & $1(10.0)$ & \multirow[t]{2}{*}{0.39} \\
\hline$\geq 3$ & $90(72.0)$ & $9(90.0)$ & \\
\hline \multicolumn{4}{|l|}{ CCS classification } \\
\hline$<3$ & $106(84.8)$ & $5(50.0)$ & \multirow[t]{2}{*}{$0.02 *$} \\
\hline$\geq 3$ & $19(15.2)$ & $5(50.0)$ & \\
\hline LAD disease & $122(97.6)$ & $10(100.0)$ & 1.00 \\
\hline LCX disease & $111(88.8)$ & $9(90.0)$ & 1.00 \\
\hline RCA disease & $104(83.2)$ & $9(90.0)$ & 0.91 \\
\hline LMT disease & $19(15.2)$ & $1(10.0)$ & 1.00 \\
\hline Triple vessel disease & $93(74.4)$ & $8(80)$ & 0.99 \\
\hline \multicolumn{4}{|l|}{ Past medical history } \\
\hline Congestive heart failure & $22(17.6)$ & $6(60.0)$ & $<0.01 * *$ \\
\hline Unstable angina & $41(32.8)$ & $5(50.0)$ & 0.50 \\
\hline Myocardial infarction & $32(25.6)$ & $5(50.0)$ & 0.20 \\
\hline Hypertension & $90(72.0)$ & $8(80.0)$ & 0.86 \\
\hline Dyslipidemia & $64(51.2)$ & $3(30.0)$ & 0.34 \\
\hline Diabetes mellitus & $73(58.4)$ & $7(70.0)$ & 0.70 \\
\hline Current smoker & $34(27.2)$ & $3(30.0)$ & 1.00 \\
\hline COPD & $3(2.4)$ & $1(10.0)$ & 0.69 \\
\hline CKD on HD & $23(18.4)$ & $3(30.0)$ & 0.63 \\
\hline Cerebrovascular disease & $23(18.4)$ & $2(20.0)$ & 1.00 \\
\hline ICA stenosis & $20(16.0)$ & $1(10.0)$ & 0.96 \\
\hline PVD & $15(12.0)$ & $2(20.0)$ & 0.81 \\
\hline \multicolumn{4}{|l|}{ Preoperative medication } \\
\hline $\mathrm{ARB}$ & $50(40.0)$ & $1(10.0)$ & 0.12 \\
\hline ACE inhibitor & $8(6.4)$ & 0 & 0.90 \\
\hline Ca channel blocker & $52(41.6)$ & $2(20.0)$ & 0.31 \\
\hline$\beta$ blocker & $76(60.8)$ & $4(40.0)$ & 0.34 \\
\hline Statin & $80(64.0)$ & $6(60.0)$ & 1.00 \\
\hline Diuretic & $30(24.0)$ & $5(50.0)$ & 0.15 \\
\hline \multicolumn{4}{|l|}{ Echocardiography } \\
\hline $\operatorname{LVEF}(\%)$ & $59.0[49.1-63.8]$ & 35.5 [30.1-41.5] & $<0.01 * *$ \\
\hline $\mathrm{LVEF}<35 \%$ & $10(8.0)$ & $5(50.0)$ & $<0.001 * * *$ \\
\hline LVEF $<40 \%$ & $18(14.4)$ & $6(60.0)$ & $<0.01 * *$ \\
\hline IVS thickness (mm) & $10.0[9.0-12.0]$ & $10.0[9.3-11.0]$ & 0.59 \\
\hline LVPW thickness (mm) & $10.0[9.0-11.0]$ & $10.0[10.0-10.0]$ & 0.88 \\
\hline LVH (thickness $\geq 15 \mathrm{~mm}$ ) & $8(6.4)$ & $1(10.0)$ & 1.00 \\
\hline $\mathrm{E} / \mathrm{Ea}$ & $12.9[10.2-16.1]$ & 16.1 [13.5-19.0] & 0.08 \\
\hline $\mathrm{E} / \mathrm{Ea} \geq 10$ & $97(80.8)$ & $9(90.0)$ & 0.32 \\
\hline $\mathrm{E} / \mathrm{Ea} \geq 14$ & $51(42.5)$ & $9(90.0)$ & 0.29 \\
\hline $\mathrm{AS} \geq$ mild & $10(8.1)$ & $2(20.0)$ & 0.50 \\
\hline $\mathrm{AR} \geq$ mild & $35(28.0)$ & $5(50.0)$ & 0.23 \\
\hline $\mathrm{MR} \geq$ mild & $60(48.0)$ & $8(80.0)$ & 0.11 \\
\hline $\mathrm{TR} \geq$ mild & $31(24.8)$ & $4(40.0)$ & 0.50 \\
\hline TAPSE (mm) & $19.5[17.5-22.5]$ & $14.3[13.0-18.0]$ & $<0.001 * * *$ \\
\hline
\end{tabular}


Table 1 (continued)

Data were expressed as absolute numbers (percentage), means ( \pm standard deviation) or medians [interquartile range]

$O P C A B$ off-pump coronary artery bypass grafting, $C P B$ cardiopulmonary bypass, ASA PS American Society of Anesthesiologists physical status, CCS classification Canadian Cardiovascular Society functional classification, $L A D$ left anterior descending artery, $R C A$ right coronary artery, $L C X$ left circumflex artery, $L M T$ left main coronary artery, $C O P D$ chronic obstructive pulmonary disease, $C K D$ chronic kidney disease, $H D$ hemodialysis, $I C A$ internal carotid artery, $P V D$ peripheral vascular disease, $A R B$ angiotensin receptor blocker, $A C E$ angiotensin converting enzyme, $C a$ calcium, $L V E F$ left ventricular ejection fraction, IVS interventricular septum, $L V P W$ left ventricular posterior wall, $L V H$ left ventricular hypertrophy, $E$ early diastolic trans-mitral blood flow velocity, $E a$ early diastolic lateral mitral annulus tissue velocity, $A S$ aortic stenosis, $A R$ aortic regurgitation, $M R$ mitral regurgitation, TR tricuspid regurgitation, TAPSE tricuspid annular plane systolic excursion

$* P<0.05 ; * * P<0.01 ; * * * P<0.001$

conversion are shown in Table 2. One patient was converted at harvest of ITA graft because of ventricular fibrillation (VF). 7 converted patients had TAPSE less than $17 \mathrm{~mm}$ (one case at harvest of ITA graft, 2 cases at LAD anastomosis, 4 cases at RCA anastomosis). One patient in whom conversion was performed died from intractable VF of unknown cause on the first postoperative day. E/Ea was not evaluated in 6 cases because of an emergent operation with simple echocardiography assessment. There were no missing data for variables to be used in multivariate analysis and ROC curve analysis.

TAPSE, TR and experienced surgeon with $P$ values less than 0.1 in univariate analysis were included in the multivariate analysis (Table 3). Age and TAPSE were included in multiple regression analysis not as categorical but as continuous variables because there were linear relations between VIS and those variables. A normal quantile-quantile plot (normal Q-Q plot) showed that the residual of VIS had a normal distribution (Fig. 2). There was no multicollinearity among variables since all VIFs were less than 2. As a result of multiple regression analysis, a significant regression equation was found (adjusted coefficient of determination (adjusted $R^{2}$ ) of $0.161, P<0.001$ ). In addition, TAPSE (standardized partial regression coefficient $(\beta)$ of -0.173 , $P=0.044)$, TR $(\beta 0.291, P<0.001)$ and experienced surgeon $(\beta-0.187, P=0.022)$ were significant predictors of VIS (Table 4).

As shown in Fig. 3, the ROC curve of emergency conversion on TAPSE showed an optimal cut-off value of $15.0 \mathrm{~mm}$ (sensitivity of 0.600 and specificity of 0.936 ) and AUC of 0.808 (95\% confidence Interval (CI) 0.645-0.971).

\section{Discussion}

In this study, we found that TAPSE and TR were associated with intraoperative maximum VIS and that the optimal cut-off value of TAPSE to predict emergency conversion was $15 \mathrm{~mm}$. The results suggested that TAPSE and TR are independent predictors of hemodynamic instability during OPCAB and that TAPSE has better discrimination power for emergency conversion to on-pump CABG. The findings of this study can help the decision-making in terms of "whether this patient is suitable for off-pump bypass or not?".

There have been some studies on RV function during OPCAB. Kwak et al. reported that a significantly reduced RVEF accompanied by an increase in RV afterload and decrease in cardiac output (CO) was observed during anastomosis of the OM artery [17]. Couture et al. reported that heart dislocation $\left(90^{\circ}\right.$ anterior displacement) and compression of the RV to a greater extent than that of the LV are responsible for hemodynamic alterations when using suction-type stabilizers [18]. In animal experiments, a pig heart retracted with a suction tissue stabilizer caused primarily RV diastolic dysfunction without concurring valvular incompetence [25]. Emergency conversion was determined more often at RCA anastomosis than at LCX anastomosis in this study. Preoperative RV dysfunction, low TAPSE or TR, might become worse due to heart dislocation with a suctiontype stabilizer not only for LCX anastomosis but also for RCA anastomosis and result in hemodynamic instability or emergency conversion.

RV dysfunction after CABG has also been reported. TAPSE and strain of the RV significantly decreased 6 days and 3 months after OPCAB compared to those before surgery [26]. Diastolic RV function at the end of surgery and peak systolic velocities of the lateral tricuspid annulus 3 months after surgery were similarly impaired in both compared OPCAB and on-pump CABG [27, 28]. RV dysfunction due to OPCAB might already occur during surgery and lead to hemodynamic instability or emergency conversion.

Patel et al. reported that the main reasons for conversion were hypotension ischemia $(76 \%)$, hemorrhage $(8 \%)$ and VF (8\%) [4]. Emergency conversion due to hemorrhage can occur regardless of RV function and reduce the AUC of the ROC curve on TAPSE. Nevertheless, TAPSE could accurately predict emergency conversion in this study. That implied that RV systolic dysfunction is highly associated with severe hypotension and even VF during OPCAB. 
Table 2 Intraoperative and postoperative data

\begin{tabular}{|c|c|c|c|}
\hline Variables & $\begin{array}{l}\text { Completed OPCAB } \\
(n=125)\end{array}$ & Converted to CPB $(n=10)$ & $P$ value \\
\hline \multicolumn{4}{|l|}{ Intraoperative data } \\
\hline Anesthesia time (min) & 343 [315-380] & $433[391-452]$ & $<0.001 * * *$ \\
\hline Operation time (min) & $266[240-300]$ & $351[315-378]$ & $<0.001 * * *$ \\
\hline Experienced anesthesiologist & $42(33.6)$ & $2(20.0)$ & 0.50 \\
\hline Experienced surgeon & $114(91.2)$ & $9(90.0)$ & 1.00 \\
\hline Number of anastomosis & $3.0[3.0-4.0]$ & $3.5[3.0-4.0]$ & 0.84 \\
\hline Blood loss (ml) & 698 [506-1090] & 935 [593-1801] & 0.21 \\
\hline Maximum VIS & $9[6.0-13.0]$ & $10[6.3-12.8]$ & 0.64 \\
\hline \multicolumn{4}{|l|}{ Reason of conversion } \\
\hline Systemic hypotension & & $6(60.0)$ & \\
\hline Pulmonary hypertension & & $1(10.0)$ & \\
\hline Bleeding & & $1(10.0)$ & \\
\hline Ventricular fibrillation & & $2(20.0)$ & \\
\hline \multicolumn{4}{|l|}{ Timing of conversion } \\
\hline Harvest of ITA graft & & $1(10.0)$ & \\
\hline Anastomosis to LAD & & $3(30.0)$ & \\
\hline Anastomosis to RCA & & $5(50.0)$ & \\
\hline Anastomosis to LCX & & $1(10.0)$ & \\
\hline \multicolumn{4}{|l|}{ Postoperative data } \\
\hline Death within POD 30 & 0 & $1(10.0)$ & 0.10 \\
\hline Graft occlusion & $19(15.6)$ & $1(10.0)$ & 1.00 \\
\hline Respiratory failure & 0 & 0 & \\
\hline Acute kidney injury & $7(6.9)$ & $1(14.3)$ & 1.00 \\
\hline Stroke & $4(3.2)$ & 0 & 1.00 \\
\hline Wound infection & 0 & 0 & \\
\hline Bleeding & $1(0.8)$ & 0 & 1.00 \\
\hline Ventilator $\geq 12 \mathrm{~h}$ & $7(5.6)$ & $3(30.0)$ & $0.03 *$ \\
\hline VIS is not $0 \geq 12 \mathrm{~h}$ & $31(24.8)$ & $4(40.0)$ & 0.50 \\
\hline ICU stay $\geq 24 \mathrm{~h}$ & $16(12.8)$ & $5(50.0)$ & $<0.01 * *$ \\
\hline Hospital stay $\geq 30$ days & $14(11.2)$ & $4(40.0)$ & $0.04 *$ \\
\hline
\end{tabular}

Data were expressed as absolute numbers (percentage), means ( \pm standard deviation) or medians [interquartile range]

$O P C A B$ off-pump coronary artery bypass grafting, $C P B$ cardiopulmonary bypass, VIS vasoactive-inotropic score, ITA internal thoracic artery, $L A D$ left anterior descending artery, $R C A$ right coronary artery, $L C X$ left circumflex artery, $P O D$ postoperative day, $I C U$ intensive care unit

$* P<0.05 ; * * P<0.01 ; * * * P<0.001$
Urgent surgery, TVD, LMT disease and CHF were not associated with VIS in contrast to results of previous studies $[5-8,11-13]$. There were many urgent cases in which IABP or scheduled on-pump CABG was performed preoperatively and these cases were excluded from this study. Severity of coronary artery stenosis of $75 \%$ to $100 \%$ was not considered in TVD and LMT disease. Similarly, the severity of CHF was not considered. That might have affected the results obtained by using these variables in multivariate analysis.

There are several limitations in this study. First, maximum VIS within $24 \mathrm{~h}$ after ICU admission in cardiac surgery is a good predictor of worse outcomes; however, there is little evidence that intraoperative maximum VIS represents hemodynamics or postoperative complications in OPCAB. Yamazaki et al. reported that a high VIS at the end of adult cardiac surgery on CPB was associated with high rates of morbidity and mortality [29]. Second, although midazolam, propofol, sevoflurane, fentanyl, remifentanil, ephedrine, phenylephrine, and fluid and blood transfusion volumes could affect VIS, they were not included in multiple regression analysis. Third, pulmonary artery catheter was inserted in all subjects. Insertion of the catheter could worsen TR and hemodynamics. In addition, the mechanism of TR was not considered. Fourth, transthoracic echocardiography was performed at various times from just before the surgery to one month before. 
Table 3 Simple regression analysis to predict vasoactive-inotropic score

\begin{tabular}{lrrrc}
\hline Variables & \multicolumn{1}{c}{$B$} & SE & $T$ value & $P$ value \\
\hline CCS classification $\geq 3$ & 0.85 & 1.38 & 0.61 & 0.54 \\
Myocardial infarction & 1.68 & 1.18 & 1.42 & 0.16 \\
Diabetes mellitus & -0.43 & 1.08 & -0.40 & 0.69 \\
Cerebrovascular disease & 0.35 & 1.36 & 0.26 & 0.80 \\
LVEF $<35 \%$ & 2.50 & 1.67 & 1.49 & 0.14 \\
LVEF $<40 \%$ & 1.56 & 1.38 & 1.13 & 0.26 \\
LVH (thickness $\geq 15 \mathrm{~mm}$ ) & 1.12 & 2.12 & 0.53 & 0.60 \\
E/Ea $\geq 10$ & 1.15 & 1.42 & 0.81 & 0.42 \\
E/Ea $\geq 14$ & 1.73 & 1.09 & 1.60 & 0.11 \\
MR $\geq$ mild & 0.76 & 1.06 & 0.72 & 0.47 \\
TR $\geq$ mild & 4.90 & 1.13 & 4.33 & $<0.001^{* * *}$ \\
TAPSE (mm) & -0.34 & 0.15 & -2.25 & $0.03^{*}$ \\
Experienced anesthesiologist & 1.67 & 1.12 & 1.49 & 0.14 \\
Experienced surgeon & -4.93 & 1.81 & -2.72 & $<0.01^{* *}$
\end{tabular}

$B$ partial regression coefficient, $S E$ standard error, CCS classification Canadian Cardiovascular Society functional classification, $L V E F$ left ventricular ejection fraction, $L V H$ left ventricular hypertrophy, $E$ early diastolic trans-mitral blood flow velocity, $E a$ early diastolic lateral mitral annulus tissue velocity, $M R$ mitral regurgitation; $T R$ tricuspid regurgitation, TAPSE tricuspid annular plane systolic excursion

$* P<0.05 ; * * P<0.01 ; * * * P<0.001$

Furthermore, RV function indicators other than TAPSE and TR could not be assessed. Fifth, the patient's physique and cardiac size were not taken into account in TAPSE. Sixth, we decided the variables for multiple regression analysis based on previous reports about emergency conversion or hemodynamics of OPCAB [5-16]. It is possible that unknown confounding factors caused bias. In

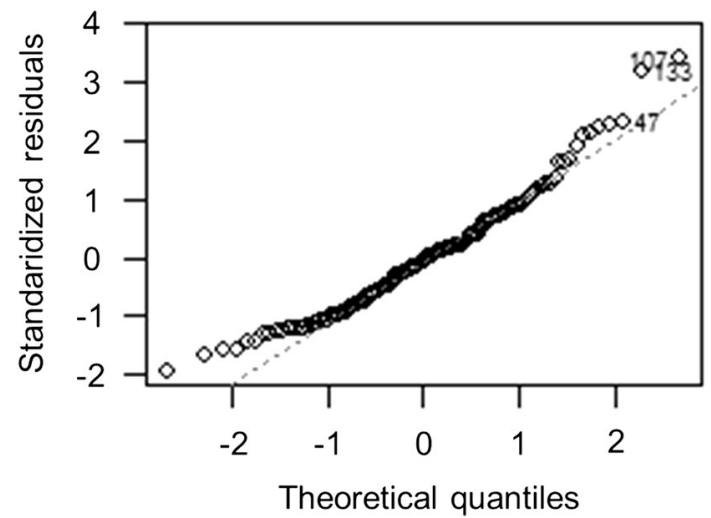

Fig. 2 Normal quantile-quantile plot. Normal quantile-quantile plot (Normal Q-Q plot) showed that the residual of VIS had a normal distribution

this study, there was a positive weak correlation between TAPSE and LVEF (Spearman's rank coefficient 0.294, $P<0.001)$. This is a limitation in all retrospective studies. Finally, it is difficult to generalize the ROC curve based on only 10 converted patients.

\section{Conclusion}

Preoperative TAPSE and TR were significantly associated with intraoperative maximum VIS in OPCAB and the optimal cut-off value of TAPSE to predict emergency conversion was $15 \mathrm{~mm}$. Further large-scale prospective studies are needed.
Table 4 Multiple regression analysis to predict vasoactiveinotropic score

\begin{tabular}{lccrrc}
\hline Variables & \multicolumn{1}{l}{ B $[95 \% \mathrm{CI}]$} & $\mathrm{SE} \mathrm{B}$ & \multicolumn{1}{c}{$\beta$} & $T$ value & $P$ value \\
\hline Intercept & $14.016[4.331,23.700]$ & 4.893 & $<0.001$ & 2.864 & $<0.01^{* *}$ \\
Age (year) & $0.038[-0.056,0.131]$ & 0.047 & 0.066 & 0.796 & 0.428 \\
Male & $-0.183[-2.580,2.214]$ & 1.211 & -0.012 & -0.151 & 0.880 \\
Urgent surgery & $2.104[-1.496,5.705]$ & 1.819 & 0.094 & 1.157 & 0.250 \\
LMT disease & $0.534[-2.280,3.347]$ & 1.422 & 0.031 & 0.375 & 0.708 \\
Triple vessel disease & $1.845[-0.399,4.089]$ & 1.134 & 0.131 & 1.627 & 0.106 \\
Congestive heart failure & $-0.487[-3.022,2.049]$ & 1.281 & -0.032 & -0.380 & 0.705 \\
TR $\geq$ mild & $4.054[1.690,6.417]$ & 1.194 & 0.291 & 3.394 & $<0.001^{* * *}$ \\
TAPSE (mm) & $-0.302[-0.597,-0.008]$ & 0.149 & -0.173 & -2.030 & $0.044^{*}$ \\
experienced surgeon & $-4.012[-7.435,-0.588]$ & 1.730 & -0.187 & -2.319 & $0.022^{*}$ \\
\hline
\end{tabular}

$B$ partial regression coefficient, $C I$ confidence interval, $S E$ standard error, $\beta$ standardized partial regression coefficient, $L M T$ left main coronary artery, TR tricuspid regurgitation, TAPSE tricuspid annular plane systolic excursion

$* P<0.05 ; * * P<0.01 ; * * * P<0.001$ 


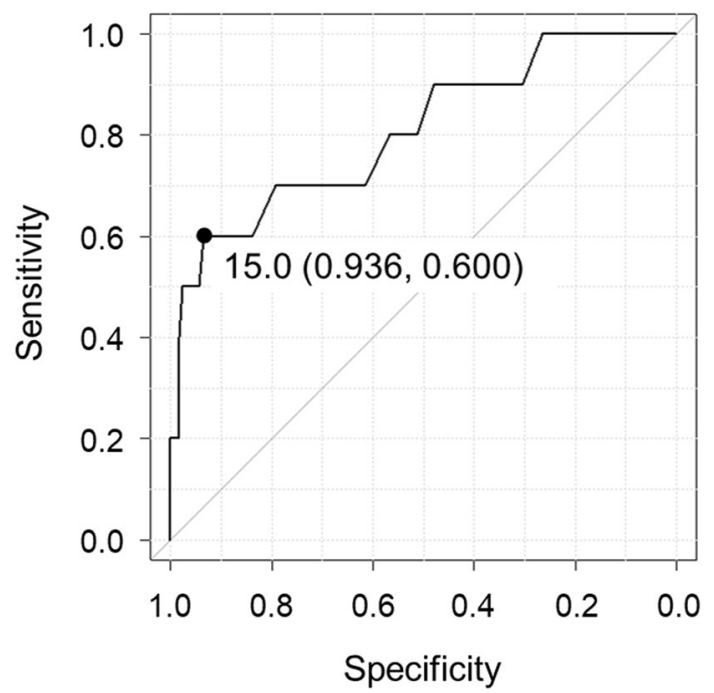

Fig. 3 Receiver operating characteristic (ROC) curve of emergency conversion on tricuspid annular plane systolic excursion (TAPSE). The ROC curve showed that the optimal cut-off value of TAPSE was $15.0 \mathrm{~mm}$ (sensitivity of 0.600 and specificity of 0.936 ) with AUC of 0.808 (95\% CI 0.645-0.971)

Acknowledgements We would like to thank SES translation and proofreading service (E-mail: nt9s-chsh@asahi-net.or.jp) for English language editing.

Author contributions This manuscript has been read and approved by all the authors. Each author's individual contribution is below: TK: This author helped the study design, study conduct, data analysis and manuscript preparation. YY: This author helped the data interpretation, confirmation of statistical methods and manuscript review. SY: This author helped the study design, study conduct and manuscript review. MY: This author helped the data interpretation, confirmation of statistical methods and manuscript review.

Funding None.

\section{Compliance with ethical standards}

Conflict of interest statement Tatsuya Kunigo declares that he has no conflict of interest. Yusuke Yoshikawa declares that he has no conflict of interest. Shuji Yamamoto declares that he has no conflict of interest. Michiaki Yamakage declares that he has no conflict of interest.

Ethical approval This study was approved by the Institutional Review Board of Obihiro Kosei General Hospital, Hokkaido, Japan (No. 2020-005).

\section{References}

1. Puskas JD, Thourani VH, Kilgo P, Cooper W, Vassiliades T, Vega $\mathrm{JD}$, et al. Off-pump coronary artery bypass disproportionately benefits high-risk patients. Ann Thorac Surg. 2009;88:1142-7.
2. Polomsky M, He X, O'Brien SM, Puskas JD. Outcomes of offpump versus on-pump coronary artery bypass grafting: Impact of preoperative risk. J Thorac Cardiovasc Surg. 2013;145:1193-8.

3. Kowalewski M, Pawliszak W, Malvindi PG, Bokszanski MP, Perlinski D, Raffa GM, et al. Off-pump coronary artery bypass grafting improves short-term outcomes in high-risk patients compared with on-pump coronary artery bypass grafting: Meta-analysis. J Thorac Cardiovasc Surg. 2016;151:60-77.

4. Patel NC, Patel NU, Loulmet DF, McCabe JC, Subramanian VA. Emergency conversion to cardiopulmonary bypass during attempted off-pump revascularization results in increased morbidity and mortality. J Thorac Cardiovasc Surg. 2004;128:655-61.

5. Jin R, Hiratzka LF, Grunkemeier GL, Krause A, Page US 3rd. Aborted off-pump coronary artery bypass patients have much worse outcomes than on-pump or successful off-pump patients. Circulation. 2005;30(112):I332-7.

6. Keeling B, Thourani V, Aliawadi G, Kim S, Cyr D, Badhwar V, et al. Conversion from off-pump coronary artery bypass grafting to on-pump coronary artery bypass grafting. Ann Thorac Surg. 2017;104:1267-74.

7. Miao N, Yang F, Du Z, Jiang C, Hao X, Wang J, et al. Mortality risk factors from converting off-pump coronary artery bypass to on-pump coronary artery bypass. Perfusion. 2017;32:554-60.

8. Chowdhury R, White D, Kilgo P, Puskas JD, Thourani VH, Chen EP, et al. Risk factors for conversion to cardiopulmonary bypass during off-pump coronary artery bypass surgery. Ann Thorac Surg. 2012;93:1936-41.

9. Novitzky D, Baltz JH, Hattler B, Collins JF, Kozora E, Shroyer $\mathrm{AL}$, et al. Outcomes after conversion in the veterans affairs randomized on versus off bypass trial. Ann Thorac Surg. 2011;92:2147-54.

10. Légaré JF, Buth KJ, Hirsch GM. Conversion to on pump from $\mathrm{OPCAB}$ is associated with increased mortality: results from a randomized controlled trial. Eur J Cardiothorac Surg. 2005;27:296-301.

11. Edgerton JR, Dewey TM, Magee MJ, Herbert MA, Prince SL, Jones KK, et al. Conversion in off-pump coronary artery bypass grafting: an analysis of predictors and outcomes. Ann Thorac Surg. 2003;76:1138-42.

12. Borde DP, Asegaonkar B, Apsingekar P, Khade S, Futane S, Khodve B, et al. Intraoperative conversion to on-pump coronary artery bypass grafting is independently associated with higher mortality in patients undergoing off-pump coronary artery bypass grafting: a propensity-matched analysis. Ann Card Anaesth. 2016;19:475-80.

13. Li Z, Amsterdam EA, Danielsen B, Hoegh H, Young JN, Armstrong EJ. Intraoperative conversion from off-pump to on-pump coronary artery bypass is associated with increased 30-day hospital readmission. Ann Thorac Surg. 2014;98:16-22.

14. Mishra M, Shrivastava S, Dhar A, Bapna R, Mishra A, Meharwal ZS, et al. A prospective evaluation of hemodynamic instability during off-pump coronary artery bypass surgery. J Cardiothorac Vasc Anesth. 2003;17:452-8.

15. Omae T, Kakihana Y, Mastunaga A, Tsuneyoshi I, Kawasaki K, Kanmura Y, et al. Hemodynamic changes during off-pump coronary artery bypass anastomosis in patients with coexisting mitral regurgitation: improvement with milrinone. Anesth Analg. 2005;101:2-8.

16. Chakravarthy M, Prabhakumar D, Patil TA, George A, Jawali V. Conversion during off-pump coronary artery bypass graft surgery: a case-control study. Ann Card Anaesth. 2019;22:18-23.

17. Kwak YL, Oh YJ, Jung SM, Yoo KJ, Lee JH, Hong YW. Change in right ventricular function during off-pump coronary artery bypass graft surgery. Eur J Cardiothorac Surg. 2004;25:572-7. 
18. Couture P, Denault A, Limoges P, Sheridan P, Babin D, Cartier R. Mechanisms of hemodynamic changes during off-pump coronary artery bypass surgery. Can J Anaesth. 2002;49:835-49.

19. Gaies MG, Gurney JG, Yen AH, Napoli ML, Gajarski RJ, Ohye RG, et al. Vasoactive-inotropic score as a predictor of morbidity and mortality in infants after cardiopulmonary bypass. Pediatr Crit Care Med. 2010;11:234-8.

20. Gaies MG, Jeffries HE, Niebler RA, Pasquali SK, Donohue JE, $\mathrm{Yu}$ S, et al. Vasoactive-inotropic score is associated with outcome after infant cardiac surgery: an analysis from the Pediatric Cardiac Critical Care Consortium and Virtual PICU System Registries. Pediatr Crit Care Med. 2014;15:529-37.

21. Koponen T, Karttunen J, Musialowicz T, Pietiläinen L, Uusaro A, Lahtinen P. Vasoactive-inotropic score and the prediction of morbidity and mortality after cardiac surgery. Br J Anaesth. 2019;122:428-36.

22. Ting PC, Wu VC, Liao CC, Chou AH, Tsai FC, Lin PJ, et al. Preoperative right ventricular dysfunction indicates high vasoactive support needed after cardiac surgery. J Cardiothorac Vasc Anesth. 2019;33:686-93.

23. Lang RM, Badano LP, Mor-Avi V, Afilalo J, Armstrong A, Ernande L, et al. Recommendations for cardiac chamber quantification by echocardiography in adults: an update from the American Society of Echocardiography and the European Association of Cardiovascular Imaging. J Am Soc Echocardiogr. 2015;28(1):139.e14.

24. Kanda Y. Investigation of the freely available easy-to-use software 'EZR' for medical statistics. Bone Marrow Transplant. 2013;48:452-8.
25. Gründeman PF, Borst C, Verlaan CW, Meijburg H, Mouës CM, Jansen EW. Exposure of circumflex branches in the tilted, beating porcine heart: echocardiographic evidence of right ventricular deformation and the effect of right or left heart bypass. J Thorac Cardiovasc Surg. 1999;118:316-23.

26. Khani M, Hosseintash M, Foroughi M, Naderian M, Khaheshi I. Assessment of the effect of off-pump coronary artery bypass $(\mathrm{OPCAB})$ surgery on right ventricle function using strain and strain rate imaging. Cardiovasc Diagn Ther. 2016;6:138-43.

27. Michaux I, Filipovic M, Skarvan K, Schneiter S, Schumann R, Zerkowski HR, et al. Effects of on-pump versus off-pump coronary artery bypass graft surgery on right ventricular function. J Thorac Cardiovasc Surg. 2006;131:1281-8.

28. Michaux I, Filipovic M, Skarvan K, Bolliger D, Schumann R, Bernet $\mathrm{F}$, et al. A randomized comparison of right ventricular function after on-pump versus off-pump coronary artery bypass graft surgery. J Thorac Cardiovasc Surg. 2011;141:361-7.

29. Yamazaki Y, Oba K, Matsui Y, Morimoto Y. Vasoactive-inotropic score as a predictor of morbidity and mortality in adults after cardiac surgery with cardiopulmonary bypass. J Anesth. 2018;32:167-73.

Publisher's Note Springer Nature remains neutral with regard to jurisdictional claims in published maps and institutional affiliations. 